\title{
Alternative Complement Pathway Activation Increases Mortality in a Model of Burn Injury in Mice
}

\author{
Jeffrey A. Gelfand, Matthias Donelan, Alexandra Hawiger, \\ and John F. Burke, Department of Medicine, Tufts-New England Medical \\ Center, Boston, Massachusetts 02111; Department of Surgery, Massachusetts \\ General Hospital, Boston, Massachusetts 02114
}

\begin{abstract}
A B S T R A C T We have studied the role of the complement system in burn injury in an experimental model in mice. A $25 \%$ body surface area, full-thickness scald wound was produced in anesthetized animals. Massive activation of the alternative complement pathway, but not the classical pathway, was seen. This activation was associated with the generation of neutrophil aggregating activity in the plasma, neutrophil aggregates in the lungs, increased pulmonary vascular permeability, and increased lung edema formation. Decomplementation with cobra venom factor (CVF) or genetic C5 deficiency diminished these pathologic changes, and CVF pretreatment substantially reduced burn mortality in the first $24 \mathrm{~h}$. Preliminary data show that human burn patients have a similar pattern of complement activation involving predominantly the alternative pathway, indicating the possible relevance of the murine model to human disease.
\end{abstract}

\section{INTRODUCTION}

Burn injury is a major medical problem. Estimates suggest that $\sim 2$ million Americans suffer significant burns annually, that $\sim 120,000-140,000$ require some form of hospitalization, and 8,000-10,000 die from burns (1). Despite marked improvements in care, shock, shock lung, and bacterial sepsis remain major complications of burn injury. In one review of the causes of death in 230 burn patients, shock was the primary cause in $14 \%$, nonthermal pulmonary injury in $14 \%$, and sepsis in $20 \%$. In another series, shock caused death in $15 \%$, and sepsis accounted for over half of the deaths $(1,2)$.

Several recent reports have noted an association of massive complement activation with shock lung and

A preliminary report of these findings was published in abstract form in 1980. Surg. Forum. 31: 80.

Received for publication 21 April 1982 and in revised form 17 August 1982. related syndromes (3-10). In addition, complement activation is thought to be a contributing factor to cardiovascular collapse in septic shock (11-14). The generation of anaphylatoxins C3a and C5a, and the subsequent stimulation and aggregation of neutrophils are thought to be involved in both septic shock and shock lung (3-14).

A number of investigators have noted hypocomplementemia after burn injury both in animals and in humans (15-27). We report new data in a murine model of thermal injury that demonstrate: $(a)$ massive activation of the complement system in the initial two hours following injury; $(b)$ the alternative pathway is the primary pathway of activation; (c) terminal complement components are not depleted to the same degree as is the initial alternative pathway activity; $(d)$ significant in vitro neutrophil aggregating activity is found in the serum and plasma of burned animals; (e) neutrophil aggregation occurs in vivo in the lungs of burned animals; $(f)$ the lungs of burned animals show evidence of increased edema formation, which is partly complement dependent and requires C5; and (g) prior complement depletion substantially increases survival from burn injury. In addition, preliminary data from studies of human burn victims show considerable concordance with our findings in the murine model, namely, massive activation of the alternative complement pathway.

\section{METHODS}

Animals. For complement studies, C57 BL/6 male mice, $6 \mathrm{wk}$ old and $25 \mathrm{~g}$ were used. For mortality studies, either C57 BL/6 or CD-1 (outbred) male mice, of similar age and weight, were used.

Experimental model of thermal injury. Animals were anesthetized with intraperitoneal pentobarbital, placed in an insulating fixed area shield, dorsum exposed, and immersed in a water bath of $80^{\circ} \mathrm{C}$ for $30 \mathrm{~s}$. This produced a full-thickness burn, of $\sim 25 \%$ of body surface area (BSA). For survival studies, animals were immediately resuscitated 
postburn with $3 \mathrm{ml}$ i.p. of sterile normal saline. For complement studies, no normal saline was administered.

A single blood sample was obtained from anesthetized, control animals (time 0 ), and from animals at $15,30,60$, and $120 \mathrm{~min}$ postburn. Samples were collected into $1.5-\mathrm{ml}$ polystyrene centrifuge tubes in an ice bath. After clotting for 30 min on ice, tubes were centrifuged at $4,000 \mathrm{~g}$ at $4^{\circ} \mathrm{C}$. Equal volumes of serum from two to four animals from each point were then pooled. For the purpose of statistical analysis, each pooled serum was treated as a single sample. At least four individual pools of sera were used at each time point.

Complement depletion ( $>80 \%$ of alternative pathway activity) was effected by the intraperitoneal injection of cobra venom factor (CVF,' Naja haje, Cordis Laboratories, Miami, FL), $200 \mathrm{U} / \mathrm{kg}$, as a single dose $3.5 \mathrm{~h}$ preburn. Control animals received an equal volume of buffer intraperitoneally (28).

$\mathrm{CH}_{50}$ assay. An adaptation of the murine $\mathrm{CH}_{50}$ assay developed by Berden et al. (29) was used.

Alternative pathway hemolytic titers $\left(\mathrm{APH}_{50}\right)$. An assay developed in our laboratory for the measurement of the murine alternative pathway was used (30). Briefly, the assay used ${ }^{51} \mathrm{Cr}$ release from rabbit erythrocytes in serum chelated with $\mathrm{Mg}^{2+}$-EGTA.

C4 assay. A modification of the assay by Atkinson et al. (31) was used.

C3 assay. Mouse C3 was determined by radial immunodiffusion, using standard techniques.

Crossed immunoelectrophoresis. Crossed immunoelectrophoresis of sera from burned mice was carried out using standard techniques with anti-mouse C3.

Hemolytic C8 assay. Sheep ${ }^{51} \mathrm{Cr}$ EA IgG were prepared, using low ionic strength veronal buffer (0.09 molar) and standardized at $1.5 \times 10^{8}$ cells $/ \mathrm{ml}$. Human C8-deficient serum (C8D) was diluted 1:50 in buffer. $50 \mu \mathrm{l}$ of cells were incubated with $100 \mu \mathrm{l}$ of $\mathrm{C} 8 \mathrm{D}(1: 50)$ for $1 \mathrm{~h}$ at $37^{\circ} \mathrm{C}$, washed, and resuspended. $100 \mu \mathrm{l}$ mouse serum serially diluted in EDTA $(0.01 \mathrm{M})$ chelated veronal buffered saline, followed by $100 \mu \mathrm{l}$ of C8D (1:50) as a source of C9 was then added to the reaction mixture. The dilution of mouse serum producing $50 \%$ hemolysis of the C8D incubated-EA IgG was then calculated to determine the mouse $\mathrm{C} 8$ titer.

Neutrophil aggregation assay. Mouse neutrophils were obtained by injecting mice intraperitoneally with $1 \mathrm{ml}$ of $15 \%$ solution of sodium caseinate in sterile phosphate-buffered saline. $16 \mathrm{~h}$ later, leukocytes were harvested by peritoneal lavage using modified Hanks' buffered saline solution (HBSS) with heparin $20 \mathrm{U} / \mathrm{ml}$. The technique developed by Craddock et al. (32-34) was used. Neutrophils were purified by Hypaque/Ficoll density gradient centrifugation, washed, and resuspended in complete HBSS, adjusting the cell concentration to $2 \times 10^{4} / \mathrm{mm}^{3}$. Cytochalasin-B was added to the cell suspension. $0.5 \mathrm{ml}$ of the neutrophil suspension was placed in a siliconized cuvette, with siliconized stirrer, and incubated at $37^{\circ} \mathrm{C}$ in a standard platelet aggregometer. 50 $\mu \mathrm{l}$ of test plasma was then added to the cuvette, and light transmission was recorded.

Lung edema and pulmonary vascular permeability. Edema formation in the lungs was measured in control and burned animals (120 min postburn). Animals were killed, lungs were placed in preweighed aluminum weighing dishes,

\footnotetext{
${ }^{1}$ Abbreviations used in this paper: $\mathrm{APH}_{50}$, alternative pathway hemolytic titers; BSA, body surface area; C8D, C8deficient serum; CVF, cobra venom factor; $\mathrm{CH}_{50}$, classical pathway activity; HBSS, Hanks' buffered saline solution.
}

weighed, and placed in a drying oven at $120^{\circ} \mathrm{C}$ for $24 \mathrm{~h}$. The number of milligrams of tissue $\mathrm{H}_{2} \mathrm{O}$ per milligram dry lung weight was calculated.

Pulmonary vascular permeability was measured by quantitating ${ }^{131} \mathrm{I}$-labeled albumin accumulation in the lungs. ${ }^{131} \mathrm{I}-$ human albumin (Albumatope, E. R. Squibb \& Sons, Princeton, $\mathrm{NJ}$ ), was injected via tail vein. Mice were subsequently anesthetized, burned, and $120 \mathrm{~min}$ later, killed. Plasma was obtained, and the lungs dissected and counted. For each animal, ${ }^{131}$ I-albumin counts per minute were determined per $1 \mathrm{ml}$ of plasma, the total lung ${ }^{131} \mathrm{I}$ counts per minute were determined, and divided by the counts per minute per milliliter of plasma. The result obtained is the volume of plasma in the lung. Extravasation of albumin in the lung is reflected by an increase in total lung plasma. The validity of measuring lung ${ }^{131} \mathrm{I}$-albumin accumulation as an assay of pulmonary alveolar capillary bed integrity was recently demonstrated by Hosea et al. (8).

\section{RESULTS}

Alternative pathway hemolytic activity, expressed as the percent initial activity, decreased rapidly over the first $60 \mathrm{~min}$. Approximately $75 \%$ of alternative pathway hemolytic activity was consumed in the first 15 $\mathrm{min}$; at $60 \mathrm{~min}$, all alternative pathway activity was depleted (Fig. 1). In contrast, at the nadir of $\mathrm{CH}_{50}$ activity (30 min), only $33 \%$ of the initial classical pathway hemolytic was consumed. By 120 minutes, alternative complement pathway hemolytic activity was only $8 \%$ of initial, preburn levels; in contrast, classical pathway activity $\left(\mathrm{CH}_{50}\right)$ was $112 \%$ of preburn levels.

These data, showing profound loss of $\mathrm{APH}_{50}$ activity, with little loss of $\mathrm{CH}_{50}$ activity, suggested that the alternative pathway was the primary pathway of activation. To further test this hypothesis, we assayed these samples for loss of hemolytic C4 activity, a sensitive indicator of classical pathway activation. As can be seen in Fig. 1 , there was a significant $(P<0.05)$ drop in $\mathrm{C} 4$ titers at 30 and 120 min postburn, indicating some activation of $\mathrm{C} 4$, and thus activation of the classical pathway. The reason for the apparent jump at $60 \mathrm{~min}$ is unclear, but a similar biphasic pattern was seen for $\mathrm{CH}_{50}$. The greater reduction of alternative pathway activity than that of $\mathrm{CH} 50$ or $\mathrm{C} 4$ was significant at all postburn time points $(P<0.05$, Wilcoxon rank sum test), suggesting preferential activation of the alternative pathway.

We reasoned that for $\mathrm{CH}_{50}$ activity to have been left intact, despite the level of alternative pathway activation, terminal complement component (C3-C9) consumption must have been minimal. This was corroborated by the hemolytic C8 titers, which at the $60-\mathrm{min}$ postburn nadir was $76 \%$ of their initial level (Fig. 1).

The sensitivity of the hemolytic alternative pathway assay was greater than antigen $\mathrm{C} 3$ assay in reflecting actual changes in alternative pathway function as demonstrated in the following in vitro experiment, 


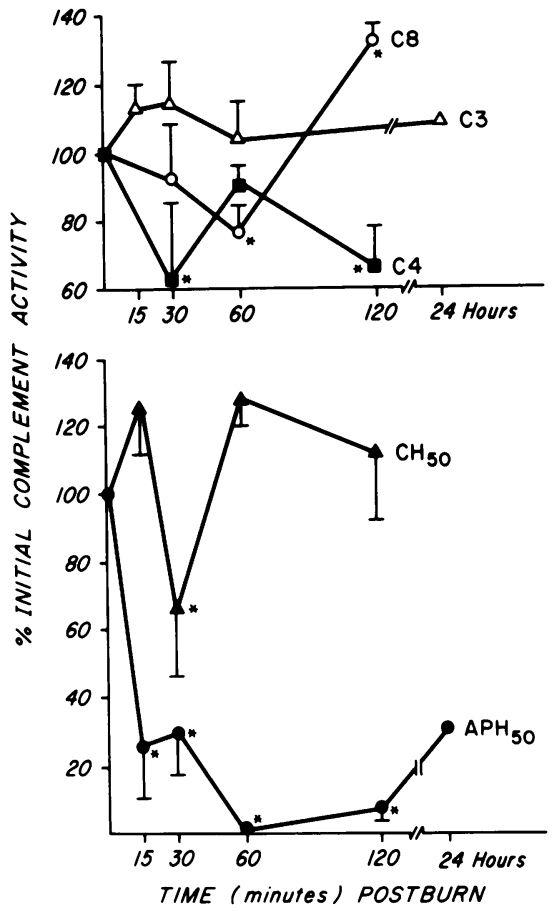

Figure 1 Complement (mean \pm SEM) after burn injury, expressed as percentage of initial (preburn) levels. $\mathrm{CH}_{50}, \mathrm{C4}$ and $\mathrm{C} 8$ hemolytic titers, and $\mathrm{APH}_{50}$ are functional assays. $\mathrm{C} 3$ antigen was determined by immunodiffusion. Each point represents the mean of at least four pooled samples, each pool containing plasma from four animals. The exception was the 24 -h point, which represents the mean of two sample pools (serum from eight animals). An asterisk marks each point differing significantly $(P<0.05)$ from the mean for unburned animals. The depletion of $\mathrm{APH}_{50}$ was significantly greater than the depletion of $\mathrm{CH}_{50}, \mathrm{C} 4$, or $\mathrm{C} 8 .(P<0.05$, Wilcoxon rank sum test).

performed in the course of investigation of our identical findings with human burn patients (see below). Pooled normal human serum from 10 donors was incubated for $30 \mathrm{~min}$ at $37^{\circ} \mathrm{C}$ with increasing amounts of zymosan, an activator of the alternative pathway. After incubation, the zymosan was pelleted, and the supernatant removed and assayed for $\mathrm{APH}_{50}$ and $\mathrm{C} 3$. As compared with serum incubated without zymosan, at a zymosan concentration of $0.2 \mathrm{mg} / \mathrm{ml}$ serum, the $\mathrm{APH}_{50}$ activity fell $50 \%$ while the $\mathrm{C} 3$ level fell only $16 \%$. At a zymosan concentration of $2 \mathrm{mg} / \mathrm{ml}$ serum, $\mathrm{APH}_{50}$ fell $100 \%$, while C3 level fell only $45 \% .^{2}$

That this is indeed activation and not protein loss (in the early hours of this injury, there is coagulation necrosis of the skin, without a weeping eschar) is un-

\footnotetext{
${ }^{2}$ Gelfand, J. A., M. B. Donelan, and J. F. Burke. Submitted
} for publication.

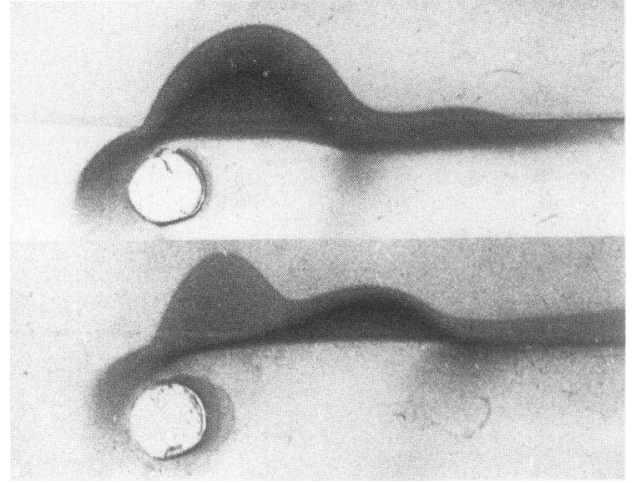

Figure 2 Crossed immunoelectrophoresis showing immunoelectrophoretic conversion (cleavage) of C3 by burn injury. The top well contained serum from an unburned, anesthetized mouse. The bottom well contained mouse serum obtained $120 \mathrm{~min}$ postburn. The anode is to the right.

derscored by the relatively small drop in total protein $($ time $0=4.6 \pm 0.45 \mathrm{~g} / \mathrm{dl} ; 60 \mathrm{~min}=3.58 \pm 0.71 \mathrm{~g} / \mathrm{dl}$ ). Although this drop is significant, it represents a decrease of only $22 \%$ of the total protein, while alternative pathway activity at the same time fell $100 \%$. In addition, crossed immunoelectrophoresis demonstrated the generation of a $\mathrm{C} 3$ cleavage product $(\mathrm{C} 3 \mathrm{bi})$ similar to that produced by serum-zymosan incubation (Fig. 2). Finally, surgical excision of a full-thickness piece of dorsal skin of identical size to the burn lesion produced no significant fall in complement levels.

Relationship of burn size to complement titers. The degree of alternative pathway depletion was directly related to the surface area injured. Fig. 3 shows

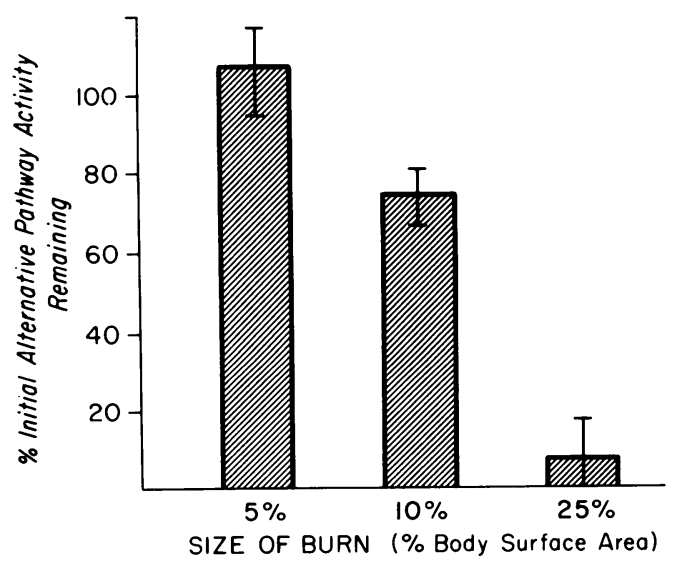

Figure 3 Mean ( \pm SEM) alternative complement pathway hemolytic activity, expressed as percent normal, remaining $2 \mathrm{~h}$ after burn injury of varying sizes ( $\%$ body surface area). For each size of burn, $n \geq 16$. Depletion of $\mathrm{APH}_{50}$ was directly proportional to burn size. 
the percent $\mathrm{APH}_{50}$ activity remaining after 5,10 , and $25 \%$ BSA full thickness burn.

Neutrophil aggregation. When heparinized (5 U/ $\mathrm{ml}$ ) plasma was assayed, neutrophil aggregating activity was observed at each postburn time point in the first $120 \mathrm{~min}$ (Fig. 4). No consistent relationship between amplitude of aggregation and time postburn was observed.

Lung changes. Normocomplementemic, burned animals develop a histologic picture of acute congestion, with interstitial edema, hemorrhage, and infarction. Neutrophil aggregates were seen in pulmonary vessels of normocomplementemic animals subject to burn injury (Fig. 5). CVF pretreated animals showed no such emboli or aggregates.

Lung tissue water was measured as an indicator of edema formation, and was found to be greater in normocomplementemic, burned animals than in CVF pretreated, burned animals [3.03 0.39 (SD) $\mathrm{mg} \mathrm{H}_{2} \mathrm{O}$ / mg dry lung tissue vs. $2.67 \pm 0.52$ (SD); $P<0.05$ by Wilcoxon rank sum test].

Intravenous injection of ${ }^{131}$ I-human albumin was used to measure alveolar capillary bed integrity (8). Extravasation of ${ }^{131} \mathrm{I}$-albumin in the lung is reflected by an increase in measured lung plasma. $2 \mathrm{~h}$ postinjury, total lung plasma was measured in genetically C.5-deficient mice (B10.D2 old $/ J$ ), coisogenic mice with normal C5 levels (B10.D2 new/J), and B10.D2 old/J mice pretreated with CVF. Mean lung plasma for burned normocomplementemic animals was $1.67 \pm 0.36 \mathrm{ml}$; for C5-deficient animals $1.02 \pm 0.12 \mathrm{ml}$; for C5-deficient,

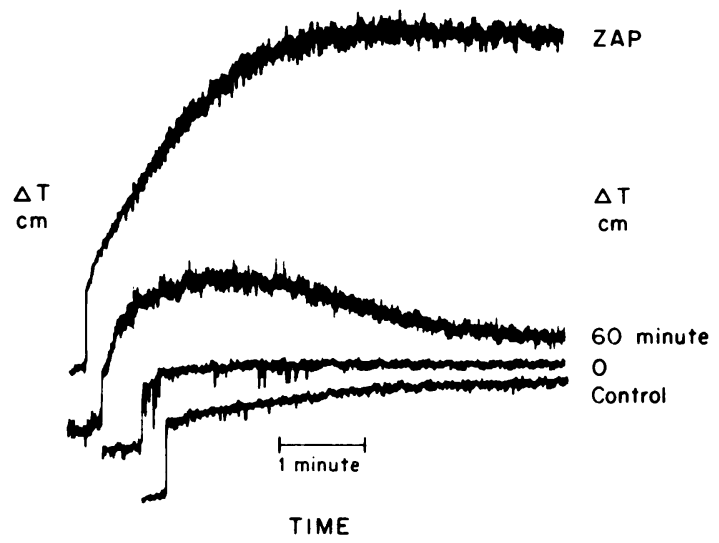

Figure 4 Neutrophil aggregation produced by plasma from a mouse $60 \mathrm{~min}$ after $25 \%$ BSA burn injury. Plasma obtained from an anesthetized mouse before burn injury (time $=0$ ) produced no aggregating activity. Normal, control mouse plasma produced no aggregation. In vitro activation of normal mouse plasma with zymosan $(2 \mathrm{mg} / \mathrm{ml})$ for $30 \mathrm{~min}$ at $37^{\circ} \mathrm{C}$ produced maximal aggregation (ZAP). Mouse neutrophils were prepared from peritoneal exudate cells subjected to Hypaque-Ficoll density gradient centrifugation.

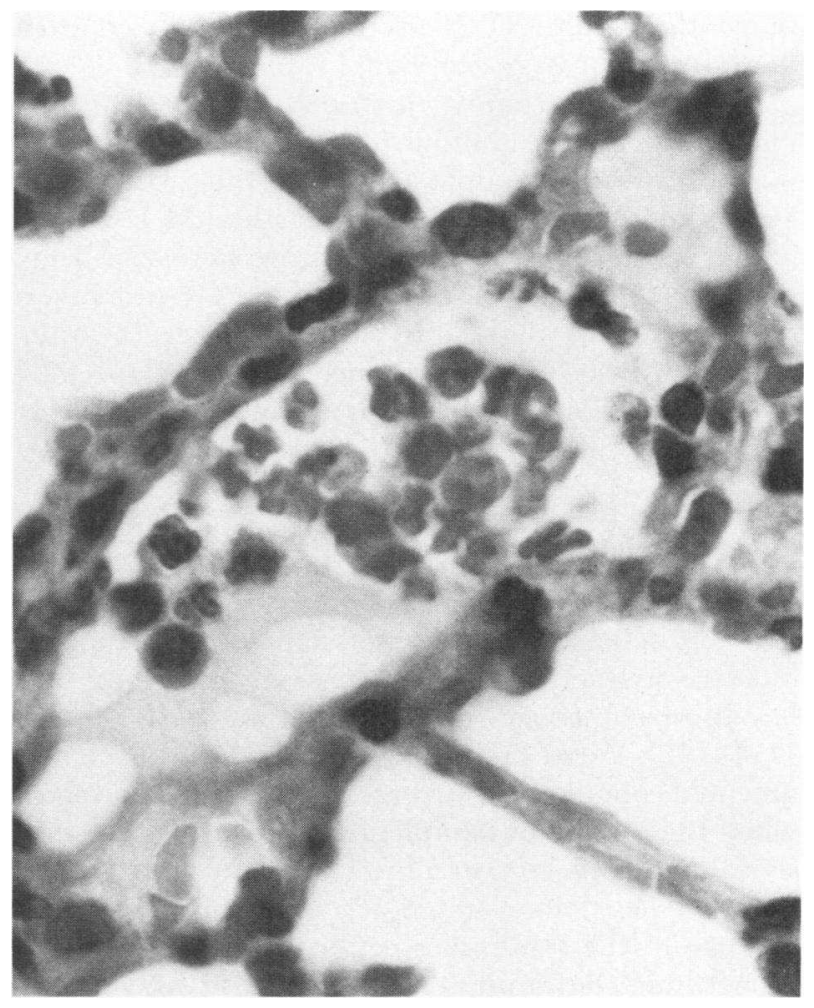

Figure 5 Aggregates of neutrophils in the lungs of a normocomplementemic mouse subjected to burn injury, and killed $2 \mathrm{~h}$ later. Aggregates were not seen in the lungs of animals pretreated with CVF to deplete them of complement activity before burn injury $(\times 200)$.

CVF-pretreated animals $1.14 \pm 0.06 \mathrm{ml}$. The burned normocomplementemic animals had significantly more lung plasma ( $P<0.05$, Student's $t$ test) than either the C5-deficient or C5-deficient CVF-pretreated, burned animals.

Early mortality. To determine whether or not complement plays a role in early mortality, we examined the effect of prior decomplementation with CVF on mortality in the first $24 \mathrm{~h}$ after burn injury. Table I

TABLE I

Effects of Prior Complement Depletion on Mortality in the First 24 h after $25 \%$ BSA Burn

\begin{tabular}{lccc}
\hline & Total & Died & Survived \\
\hline Control mice & & $\%$ & $\%$ \\
CVF treated mice & 31 & $20(64.5)$ & $11(35.5)$ \\
Total & $\frac{21}{52}$ & $\frac{2(9.5)}{22}$ & $\frac{19(90.5)}{30}$ \\
\hline
\end{tabular}

The difference between mortality in control and CVF treated groups was highly significant $(P<0.001)$ using chi-square analysis. 
shows the results. CVF pretreatment reduced early mortality from $64.5 \%$ to $9.5 \%$ (Table I).

Preliminary studies in human burn patients. Plasma from eight adult burn patients (25 to 90\% BSA) was obtained upon admission to the Burn Unit of the Massachusetts General Hospital, within $24 \mathrm{~h}$ of burn injury. Mean $\mathrm{CH}_{50}$ titers on admission were $49 \%$ below the normal mean, whereas hemolytic $\mathrm{C} 4$ titers were reduced by $53 \%$, and $\mathrm{C} 3$ by $43 \%$. However, the alternative pathway titer was reduced by a striking $92 \%$, a reduction significantly greater than that of the classical pathway $(P<0.01$, Wilcoxon paired sample test $) .{ }^{2}$

\section{DISCUSSION}

A functional complement system is necessary for normal host defense against bacteria and other pathogens, but excessive activation of this critical mediator system has also been associated with shock in sepsis $(3,5,8$, $11-14,35)$. Experiments in animals $(11,14)$ have documented complement-mediated hypotension and shock when the degree of complement activation was massive and took place over a brief period of time. Recent evidence has demonstrated activation of complement in some of the syndromes commonly associated with "shock lung" or the adult respiratory distress syndrome (3-10). In these syndromes, increased vascular permeability is associated with the extravasation of plasma, resulting in pulmonary dysfunction. A number of mediators have been implicated, but C.5a generation is thought to play a central role (3-10).

Activation of the alternative pathway is caused by bacteria, fungi, and virus-transformed cells. Acting as a recognition system as well as a mediator system, this pathway thus may function to detect cell surface alterations (36). It was recently demonstrated that thermally damaged cells in vitro would activate the alternative pathway, and a similar finding was reported for in vivo damaged tissue (37-39). Finally, thermally aggregated serum protein can activate the alternative pathway (40).

In 1957, Lowbury et al. (15) described defective alternative pathway function in burn patients. Since that time a number of studies of burn patients and experimental animals have documented profound complement abnormalitites (16-27). Heideman (25) demonstrated in vivo alternative pathway activation by thermally damaged tissue.

As with previous reports, we have observed major complement abnormalities. Our data suggest massive complement activation is proceeding primarily via the alternative pathway. While there was some initial classical pathway depletion, the degree of alternative pathway depletion was significantly greater. The minimal loss of C8 activity suggested that terminal com- ponent (C3-C9) activity was not greatly depleted. That the fall in activity was due to activation, and not simple protein loss or inhibition, is supported by the minimal fall in total protein, generation of $\mathrm{C} 3$ cleavage products, and C5a des arginine bioactivity.

Altogether, these pieces of data give us a picture of preferential activation of the alternative pathway, with generation of cleavage products (i.e., C5a), but incomplete consumption of terminal components accounting for the maintenance of $\mathrm{CH}_{50}$ activity. This is best accounted for by hypothesizing preferential consumption of early alternative pathway components, possibly through fluid phase activation and the creation of an unstable and inefficient $\mathrm{C} 3$ or $\mathrm{C} 5$ convertase. An analogy for this situation is thought to occur in the classical pathway with hereditary angioedema, where fluid phase activation of $\mathrm{Cl}$ occurs, with depletion of C.2 and C4. Terminal (C3-C9) component activity is generally near normal (41).

It is possible to hypothesize fluid phase alternative pathway activation directly on the basis of burn injury. The initial event in the activation of the alternative pathway is thought to be the hydrolysis of a thioester bond in native $\mathrm{C} .3$, generating $\mathrm{C} 3 \mathrm{~b}$. In the presence of magnesium, D, and B, C.3b can form the alternative pathway convertase, $\mathrm{C} 3 \mathrm{bBb}$, stabilized by properdin $(36,42)$. Further $\mathrm{C} 3$ cleavage to form $\mathrm{C} 3 \mathrm{~b}$ could result in formation of the C.5 cleaving enzyme, or more $\mathrm{C} 3$ convertase. Several investigators have demonstrated a marked enhancement of $\mathrm{C} 3$ cleavage or proteolysis at temperatures $>64^{\circ} \mathrm{C}$ (43). Plasma exposed to high temperature might result in the generation of fluid phase $C 3 \mathrm{~b}$, a potent activator of the alternative pathway. In the absence of a "protected site," fluid phase generated $\mathrm{C} 3 \mathrm{bBb}$ would be highly susceptible to degradation by $\beta 1 \mathrm{H}$ and C3bINA, thus forming an inefficient cleaving enzyme for terminal pathway consumption $(36,42,44-46)$. The findings of functional alternative pathway depletion, C3 cleavage, C5a generation, and incomplete C8 consumption provide tantalizing, though incomplete, support for this hypothesis.

Our data strongly suggest an important pathogenic role for the complement activation seen with burn injury. Plasma neutrophil aggregating activity and aggregates of neutrophils in pulmonary vessels have been associated with shock lung in a number of clinical and experimental investigations (3-10), and was seen with burn injury in our model. Prevention of this sudden, explosive complement activation by CVF pretreatment reduced pulmonary edema, and enhanced survival.

Finally, our preliminary data in human burn patients reveal striking similarities with the data from our murine model. In human burn patients alternative 
pathway depletion was significantly greater than that seen for the classical pathway.

Taken together, these data suggest that burn injury causes rapid and uncontrolled alternative complement pathway activation. These data further suggest that new therapeutic strategies designed to inhibit complement activation or its consequences may reduce the complications of burn injury such as "burn shock," shock lung, and infection.

\section{ACKNOWLEDGMENTS}

The authors wish to thank Diane Welch and Mary Calderazzo for typing this manuscript.

This work was supported by grants from the Medical Foundation, Boston, MA; The Posner Fund of Tufts New England Medical Center Hospital, and the National Institute of General Medical Sciences (R23GM28591).

\section{REFERENCES}

1. Curreri, W. P., A. Luterman, D. W. Braun, and G. T. Shires. 1980. Burn injury analysis of survival and hospitalization time for 937 patients. Ann. Surg. 192: 472478.

2. Sevitt, S. 1979. A review of the complications of burns, their origin and importance for illness death. J. Trauma. 19: $358-369$.

3. Hammerschmidt, D. E., L. J. Weaver, L. D. Hudson, P. R. Craddock, and H. S. Jacob. 1980. Association of complement activation and elevated plasma-C5a with adult respiratory distress syndrome. Lancet. I: 947-949.

4. Hammerschmidt, D., and P. Craddock. 1978. Complement activation and pulmonary leukostasis during nylon fiber filtration leukapheresis. Blood. 51: 721-730.

5. Jacob, H. S., P. R. Craddock, D. E. Hammerschmidt, and C. F. Moldow. 1980. Complement-induced granulocyte aggregation: an unsuspected mechanism of disease. N. Engl. J. Med. 302: 789-794.

6. Hammerschmidt, D. E., P. R. Craddock, J. McCullough, R. S. Kronenberg, A. P. Dalmasso, and H. S. Jacob. 1978. Complement activation \& pulmonary leukostasis during nylon fiber filtration leukapheresis. Blood. 51: 721-730.

7. Craddock, P. R., J. Fehr, A. P. Dalmasso, K. L. Brigham, and H. S. Jacob. 1977. Hemodialysis leukopenia. Pulmonary vascular leukostasis resulting from complement activation by dialyzer cellophane membranes. J. Clin. Invest. 59: 879-888.

8. Hosea, S., E. Brown, C. Hammer, and M. Frank. 1980. Role of complement activation in a model of adult respiratory distress syndrome. J. Clin. Invest. 66: 375-382.

9. Henson, P. M., K. McCarthy, and G. L. Larsen. 1979 Complement fragments, alveolar macrophages, and alveolitis. Am. J. Pathol. 97: 93-110.

10. Hohn, D. C., A. J. Meyers, S. T. Gherini, A. Beckman, R. E. Markison, and A. M. Churg. 1980. Production of acute pulmonary injury by leukocytes and activated complement. Surgery (St. Louis). 88: 48-58.

11. Ulevitch, R. J., C. G. Cochrane, P. M. Morrison, and W. F. Doe. 1975. Mediation systems in bacterial lipopolysaccharide-induced hypotension and disseminated intravascular coagulation. I. The role of complement. $J$. Exp. Med. 142: 1570-1590.

12. McCabe, W. R. 1973. Serum complement levels in bacteremia due to gram negative. N. Engl. J. Med. 288: 2123.
13. Fearon, D. T., S. Ruddy, P. H. Schur, and W. R. McCabe. 1975. Activation of the properdin pathway in patients with gram negative bacteremia. N. Engl. J. Med. 292: 937-940.

14. From, A. H. L., H. Gewurz, R. P. Gruninger, R. J. Pickering, and W. W. Spink. 1970. Complement in endotoxin shock: effect of complement depletion on the early hypotensive phase. Infect. Immun. 2: 38-41

15. I owbury, E. J. L., and C. R. Ricketts. 1957. Properdin and the defence of burns against infection. J. Hyg. 55: 266-275.

16. Fjellström, K. E., and G. Arturson. 1963. Changes in the human complement system following burn trauma. Acta Pathol. Microbiol. Scand. 59: 257-270.

17. Bjornson, A. B., and J. W. Alexander. 1974. Alterations of serum opsonins in patients with severe thermal injury. J. Lab. Clin. Med. 83: 372-382.

18. Bjornson, A. B., W. A. Altemeier, and H. S. Bjornson. 1976. Reduction in C3 conversion in patients with severe thermal injury. J. Trauma. 16: 905-911

19. Bjornson, A. B., H. S. Altemeier, and H. S. Bjornson. 1978. Host defense against opportunist microorganisms following trauma. II. Changes in patients with abdominal trauma and in septic patients without trauma. Ann. Surg. 188: 102-108

20. Alexander, J. E., C. K. Ogle, J. D. Stinnett, and B. G. MacMillan. 1978. A sequential, prospective analysis of immunologic abnormalities and infection following severe thermal injury. Ann. Surg. 188: 809-816.

21. Alexander, J. W., D. Stinnett, C. K. Ogle, J. D. Ogle, and M. J. Morris. 1979. A comparison of immunologic profiles and their influence on bacteremia in surgical patients with a high risk of infection. Surgery (St. Louis.) 86: 94-104.

22. Nathenson, G., M. E. Miller, K. A. Myers, A. Stitzel, and R. E. Spitzer. 1978. Decreased opsonic and chemotactic activities in sera of postburn patients and partial opsonic restoration with properdin and properdin convertase. Clin. Immunol. Immunopathol. 9: 269-276.

23. Zuckerman, L., J. A. Caprini, V. Lipp, and J. P. Vagher. 1978. Disseminated intravascular multiple systems activation (DIMSA) following thermal injury. J. Trauma. 18: 432-439.

24. Dhennin, C., G. Pinon, and J. M. Greco. 1978. Alterations of complement system following thermal injury: use in estimation of vital prognosis. J. Trauma. 18: 129133.

25. Heideman, M. 1979. The effect of thermal injury on hemodynamic, respiratory, and hematologic variables in relation to complement activation. J. Trauma. 19: 239-24:3.

26. Daniels, J. C., D. L. Larson, S. Abston, and S. E. Ritzmann. 1974. Serum protein profiles in thermal burns. II. Protease inhibitors, complement factors, with C-reactive protein. J. Trauma. 14: 153-162.

27. Farrell, M. F., N. K. Day, V. Tsakraklides, R. A. Good, and S. B. Day. 1973. Study of lymphocyte depletion and serum complement perturbations following acute burn trauma. Surgery (St. Louis). 73: 697-705.

28. Joiner, K. A., A. Hawiger, and J. A. Gelfand. 1980. The effect of cobra venom factor on alternative pathway hemolytic activity in mice. Immunol. Commun. 9: 277281 .

29. Berden, J. H., J. F. H. Hageman, and R. A. P. Koene. 1978. A sensitive haemolytic assay of mouse complement. J. Immunol. Methods. 23: 149-159. 
30. Joiner, K. A., R. Shahon, and J. A. Gelfand. 1979. A sensitive microassay for the murine alternative complement pathway. J. Immunol. Methods. 31: 283-290.

31. Atkinson, J. P., K. McGinnis, and D. Shreffler. 1980. Development and characterization of a hemolytic assay for mouse C4. J. Immunol. Methods. 33: 351-368.

32. Craddock, P. R., D. Hammerschmidt, J. C. White, A. P. Dalmasso, and H. S. Jacob. 1977. Complement (C.5a)-induced granulocyte aggregation in vitro. J. Clin. Invest. 60: 260-264.

33. Craddock, P. R., J. G. White, and H. S. Jacob. 1978. Potentiation of complement (C5a)-induced granulocyte aggregation by cytochalasin B. J. Lab. Clin. Med. 91: 490-499.

34. Hammerschmidt, D., and T. Bowers. 1980. Granulocyte aggregometry: a sensitive technique for the detection of C5a and complement activation. Blood. 55: 898-902.

35. Brown, E. J., S. W. Hosea, C. H. Hammer, C. G. Burch, and M. M. Frank. 1982. A quantitative analysis of the interactions of antipneumococcal antibody and complement in experimental pneumococcal bacteremia. J. Clin. Invest. 69: 85-98.

36. Fearon, D. T. 1979. Activation of the alternative complement pathway. In Critical Reviews in Immunology. M. Z. Atassi, editor. CRC Press, Boca Raton, FL. 1: 132

37. Heideman, M. 1979. Complement activation in vitro induced by endotoxin and injured tissue. J. Surg. Res. 26: $670-673$.

38. Baker, P. J., and S. G. Osofsky. 1980. Activation of hu- man complement by heat killed, human kidney cells grown in cell culture. J. Immunol. 124: 81-86.

39. Baker, P. J., B. P. Croker, and S. G. Osofsky. 1981. Interactions of human, cultured kidney cells with the complement system. Kidney Int. 20: 437-441.

40. Sandberg, A. L., and A. G. Olsen. 1971. Dual pathways of complement interaction with guinea pig immunoglobulins. J. Immunol. 107: 1268-1273.

41. Frank, M. M., J. A. Gelfand, and J. P. Atkinson. 1976. Hereditary angioedema: the clinical syndrome and its management. Ann. Intern. Med. 84: 580-593.

42. Fearon, D. T., and K. F. Austen. 1975. Properdin: Binding to C3b and stabilization of the C.3b-dependent C.3 convertase. J. Exp. Med. 142: 856-863.

43. Sim, R. B., and E. Sim. 1981. Autolytic fragmentation of complement components $\mathrm{C} 3$ and $\mathrm{C} 4$ under denaturing conditions, a property shared with 2-macroglobulin. Biochem. J. 193: 129-141

44. Fearon, D. T. 1978. Regulation by membrane sialic acid of $\beta 1 \mathrm{H}$-dependent decay-dissociation of amplification C.3 convertase of the alternative complement pathway. Proc. Natl. Acad. Sci. USA. 75: 1971-1975.

45. Fearon, D. T., and K. F. Austen. 1977. Activation of the alternative complement pathway with rabbit erythrocytes by circumvention of the regulatory action of endogenous control proteins. J. Exp. Med. 146: 22-33.

46. Fearon, D. T., and K. F. Austen. 1977. Activation of the alternative complement pathway due to resistance of zymosan-bound amplification convertase to endogenous regulatory mechanisms. Proc. Natl. Acad. Sci. USA. 74: $1683-1687$. 